\author{
F.Kh. Muradov* \\ Near East University, Nicosia, Turkey \\ (E-mail: firudin.muradov@neu.edu.tr)
}

\title{
Ternary semigroups of topological transformations
}

\begin{abstract}
A ternary semigroup is a nonempty set with a ternary operation which is associative. The purpose of the present paper is to give a characterization of open sets of finite-dimensional Euclidean spaces by ternary semigroups of pairs of homeomorphic transformations and extend to ternary semigroups certain results of L.M. Gluskin concerned with semigroups of homeomorphic transformations of finite-dimensional Euclidean spaces.
\end{abstract}

Keywords: Euclidean $n$-space, ternary semigroup, homeomorphic transformations.

\section{Introduction}

Lehmer [1] investigated certain triple systems called triplexes, Santiago and Sri Bala [2] developed regular and completely regular ternary semigroups. Dutta, Kar and Maity studied intra-regular ternary semigroups [3]. Wagner studied generalized heaps and generalized groups [4]. Gluskin showed that semigroups of topological transformations of bounded closed sets on Euclidean $n$-spaces define those sets exactly up to homeomorphism [5]. Mustafaev studied semiheaps of homeomorphic maps of open and closed sets of Euclidean $n$-spaces [6]. In this paper we study some properties of ternary semigroups of topological maps between open sets of Euclidean $n$-spaces.

A ternary semigroup is a nonempty set $T$ together with a ternary operation [abc] satisfying the associative law $[[a b c] d e]=[a[b c d] e]=[a b[c d e]]$ for every $a, b, c, d, e \in T$. Any semigroup can be made into a ternary semigroup by defining the ternary product to be $[a b c]=a b c$. A nonempty subset $L$ of a ternary semigroup $T$ is called a left (right, lateral) ideal of $T$, if $[T T L] \subseteq L([L T T] \subseteq L,[T L T] \subseteq L)$. A nonempty subset $A$ of a ternary semigroup $T$ is called a two sided ideal of $T$ if it is a left and right ideal of $T$. A nonempty subset $A$ of a ternary semigroup $T$ is called an ideal of $T$ if it is a left, right and lateral ideal of $T$. If the intersection $K$ of all the ideals of a ternary semigroup $T$ is not empty, we shall call $K$ the kernel of $T$. A ternary semigroup is called (left, right) simple if it does not contain any proper (left, right) ideals [7]. A ternary semigroup is simple if it does not have nontrivial homomorphisms, that is, if each of its homomorphisms is either an isomorphism or a mapping onto a ternary semigroup consisting of one element. A zero "0"of a ternary semigroup $T$ is an element such that for all $a, b \in T,[0 a b]=[a 0 b]=[a b 0]=0$. An equivalence relation $\rho$ on a ternary semigroup $T$ is said to be a left congruence if $(a, b) \in \rho \Longrightarrow([s t a],[s t b]) \in \rho$ for all $a, b, s, t \in T$. Similarly, $\rho$ is a right congruence if $(a, b) \in \rho \Longrightarrow([a s t],[b s t]) \in \rho$ for all $a, b, s, t \in T$ and a lateral congruence if $(a, b) \in \rho \Longrightarrow([s a t],[s b t]) \in \rho$ for all $a, b, s, t \in T$. An equivalence relation $\rho$ on a ternary semigroup $T$ is said to be a congruence if $\left(a, a^{\prime}\right) \in \rho,\left(b, b^{\prime}\right) \in \rho,\left(c, c^{\prime}\right) \in \rho \Longrightarrow\left([a b c],\left[a^{\prime} b^{\prime} c^{\prime}\right]\right) \in \rho$ for all $a, a^{\prime}, b, b^{\prime}, c, c^{\prime} \in T$. An equivalence relation $\rho$ on a ternary semigroup $T$ is a congruence if and only if it is a left, a right and a lateral congruence on $T[8]$.

Let $X$ and $Y$ be two nonempty sets and let $F(X, Y)$ be the set of all pairs of functions $(\gamma, \eta)$, where $\gamma: X \rightarrow Y$ and $\eta: Y \rightarrow X$. The set $F(X, Y)$ is a ternary semigroup with respect to the ternary operation

$$
\left[\left(\gamma_{1}, \eta_{1}\right)\left(\gamma_{2}, \eta_{2}\right)\left(\gamma_{3}, \eta_{3}\right)\right]=\left(\gamma_{1} \eta_{2} \gamma_{3}, \eta_{1} \gamma_{2} \eta_{3}\right)
$$

where $\left(\gamma_{1} \eta_{2} \gamma_{3}\right) x=\gamma_{1}\left(\eta_{2}\left(\gamma_{3}(x)\right)\right)$ and $\left(\eta_{1} \gamma_{2} \eta_{3}\right) y=\eta_{1}\left(\gamma_{2}\left(\eta_{3}(y)\right)\right)$.

Let $S$ be a ternary semigroup and $a$ be any element of $S$. The set $S S a \cup a$ is a left ideal of $S$ and is called the principal left ideal of $S$ generated by $a$. Consider the following symmetric and reflexive relation on the set $S$ defined by

$$
\sigma_{t}: x \sigma_{t} y \leftrightarrow x, y \in S S a \cup a,(x, y \in S) .
$$

${ }^{*}$ Corresponding author.

E-mail: firudin.muradov@neu.edu.tr 
$\overline{\sigma_{t}}$ denotes the transitive closure of $\sigma_{t}$. Each class $L_{\nu}$ of $\overline{\sigma_{t}}$ is the union of some principal left ideals of $S$ and therefore is a left ideal of $S$. The partition

$$
S=\cup L_{\nu}
$$

of the ternary semigroup $S$ into classes of $\overline{\sigma_{t}}$ is the representation of $S$ as the union of the pairwise disjoint left ideals. We say that (1) is the most fractional partition of $S$ into pairwise disjoint left ideals.

\section{Characterization of open sets of Euclidean n-spaces by ternary semigroups}

Let $\Omega_{1}$ and $\Omega_{2}$ be two open sets of a finite-dimensional Euclidean space. $H_{i}\left(\Omega_{i}, \Omega_{j}\right)$ denotes the set of all homeomorphic maps from $\Omega_{i}$ to $\Omega_{j}$, where $i, j=1,2,(i \neq j)$. Let $K_{i}\left(\Omega_{i}, \Omega_{j}\right)$ denote the set of all $a \in H_{i}\left(\Omega_{i}, \Omega_{j}\right)$ for which there is an $n$-sized element $E_{a} \subset \Omega_{j}$ (a set homeomorphic to some closed $n$-ball) and a closed set $F_{a} \subset$ $\Omega_{j}$ such that $a \Omega_{i} \subset F_{a} \subset$ Int $E_{a}$, where $i, j=1,2(i \neq j)$. Let $O H=O H\left(\Omega_{1}, \Omega_{2}\right)=H_{1}\left(\Omega_{1}, \Omega_{2}\right) \times H_{2}\left(\Omega_{2}, \Omega_{1}\right)$ be the set of all pairs of homeomorphic maps $(a, b)$, where $a \in H_{1}\left(\Omega_{1}, \Omega_{2}\right), b \in H_{2}\left(\Omega_{2}, \Omega_{1}\right)$. The set $O H$ is a ternary semigroup with respect to the ternary operation

$$
\left[\left(a_{1}, b_{1}\right)\left(a_{2}, b_{2}\right)\left(a_{3}, b_{3}\right)\right]=\left(a_{1} b_{2} a_{3}, b_{1} a_{2} b_{3}\right)
$$

Clearly, the set $K=K\left(\Omega_{1}, \Omega_{2}\right)=K_{1}\left(\Omega_{1}, \Omega_{2}\right) \times K_{2}\left(\Omega_{2}, \Omega_{1}\right)$ is a ternary subsemigroup and even an ideal of the ternary semigroup $O H$.

Theorem 1. Let $R$ and $R^{\prime}$ be finite-dimensional Euclidean spaces. Let $\Omega_{1}$ and $\Omega_{2}$ be open sets of a finite-dimensional Euclidean space $R$ and $\Omega_{1}^{\prime}$ and $\Omega_{2}^{\prime}$ be open sets of a finite-dimensional Euclidean space $R^{\prime}$. The ternary semigroups $K\left(\Omega_{1}, \Omega_{2}\right)$ and $K\left(\Omega_{1}^{\prime}, \Omega_{2}^{\prime}\right)$ are isomorphic if and only if the spaces $\Omega_{i}$ and $\Omega_{i}^{\prime}$ are homeomorphic $(i=1,2)$.

Proof. Let $\Omega_{1}$ and $\Omega_{2}$ be open subsets of a finite-dimensional Euclidean space $R$ and let $\Omega_{1}^{\prime}$ and $\Omega_{2}^{\prime}$ be open subsets of a finite-dimensional Euclidean space $R^{\prime}$. Suppose that $\xi_{1}: \Omega_{1} \rightarrow \Omega_{1}^{\prime}$ is a homeomorphism of $\Omega_{1}$ onto $\Omega_{1}^{\prime}$ and $\xi_{2}: \Omega_{2} \rightarrow \Omega_{2}^{\prime}$ is a homeomorphism of $\Omega_{2}$ onto $\Omega_{2}^{\prime}$. Then, the mapping $\varphi_{\xi_{1}, \xi_{2}}: K\left(\Omega_{1}, \Omega_{2}\right) \rightarrow K\left(\Omega_{1}^{\prime}, \Omega_{2}^{\prime}\right)$ defined by

$$
\varphi_{\xi_{1}, \xi_{2}}(a, b)=\left(\xi_{2} a \xi_{1}^{-1}, \xi_{1} b \xi_{2}^{-1}\right)
$$

is an isomorphism from $K\left(\Omega_{1}, \Omega_{2}\right)$ onto $K\left(\Omega_{1}^{\prime}, \Omega_{2}^{\prime}\right)$. The proof of the necessary condition follows from Lemmas $1-5$.

Throughout this paper the symbol $\varphi$ denotes an isomorphism $\varphi: K\left(\Omega_{1}, \Omega_{2}\right) \rightarrow K\left(\Omega_{1}^{\prime}, \Omega_{2}^{\prime}\right)$ unless otherwise stated.

Lemma 1. Let $\left(a_{1}, b_{1}\right),\left(a_{2}, b_{2}\right) \in K\left(\Omega_{1}, \Omega_{2}\right)$ such that

$$
\left(a_{2}, b_{2}\right)\left(\Omega_{1}, \Omega_{2}\right) \subseteq\left(a_{1}, b_{1}\right)\left(\Omega_{1}, \Omega_{2}\right)
$$

Then,

$$
\varphi\left(a_{2}, b_{2}\right)\left(\Omega_{1}^{\prime}, \Omega_{2}^{\prime}\right) \subset \overline{\varphi\left(a_{1}, b_{1}\right)\left(\Omega_{1}^{\prime}, \Omega_{2}^{\prime}\right)}
$$

Proof. Let $\left(a_{1}, a_{2}\right),\left(b_{1}, b_{2}\right)$ be any two elements in $K\left(\Omega_{1}, \Omega_{2}\right)$ such that

$$
\left(a_{2}, b_{2}\right)\left(\Omega_{1}, \Omega_{2}\right) \subseteq\left(a_{1}, b_{1}\right)\left(\Omega_{1}, \Omega_{2}\right)
$$

If

$$
\left[\varphi\left(a_{1}, b_{1}\right)\left(x_{1}^{\prime}, y_{1}^{\prime}\right) \varphi\left(a_{1}, b_{1}\right)\right]=\left[\varphi\left(a_{1}, b_{1}\right)\left(x_{2}^{\prime}, y_{2}^{\prime}\right) \varphi\left(a_{1}, b_{1}\right)\right]
$$

is valid for some $\left(x_{1}^{\prime}, y_{1}^{\prime}\right),\left(x_{2}^{\prime}, y_{2}^{\prime}\right) \in K\left(\Omega_{1}^{\prime}, \Omega_{2}^{\prime}\right)$, then there exist elements $\left(x_{1}, y_{1}\right),\left(x_{2}, y_{2}\right) \in K\left(\Omega_{1}, \Omega_{2}\right)$ such that $\varphi\left(x_{1}, y_{1}\right)=\left(x_{1}^{\prime}, y_{1}^{\prime}\right)$ and $\varphi\left(x_{2}, y_{2}\right)=\left(x_{2}^{\prime}, y_{2}^{\prime}\right)$. Therefore

$$
\left[\varphi\left(a_{1}, b_{1}\right) \varphi\left(x_{1}, y_{1}\right) \varphi\left(a_{1}, b_{1}\right)\right]=\left[\varphi\left(a_{1}, b_{1}\right) \varphi\left(x_{2}, y_{2}\right) \varphi\left(a_{1}, b_{1}\right)\right]
$$

From this it follows

$$
\varphi\left[\left(a_{1}, b_{1}\right)\left(x_{1}, y_{1}\right)\left(a_{1}, b_{1}\right)\right]=\varphi\left[\left(a_{1}, b_{1}\right)\left(x_{2}, y_{2}\right)\left(a_{1}, b_{1}\right)\right]
$$

and since $\varphi$ is an isomorphism of $K\left(\Omega_{1}, \Omega_{2}\right)$ onto $K\left(\Omega_{1}^{\prime}, \Omega_{2}^{\prime}\right)$ we have

$$
\left[\left(a_{1}, b_{1}\right)\left(x_{1}, y_{1}\right)\left(a_{1}, b_{1}\right)\right]=\left[\left(a_{1}, b_{1}\right)\left(x_{2}, y_{2}\right)\left(a_{1}, b_{1}\right)\right]
$$


Then,

$$
\left[\left(a_{2}, b_{2}\right)\left(x_{1}, y_{1}\right)\left(a_{2}, b_{2}\right)\right]=\left[\left(a_{2}, b_{2}\right)\left(x_{2}, y_{2}\right)\left(a_{2}, b_{2}\right)\right]
$$

or

$$
\left[\varphi\left(a_{2}, b_{2}\right) \varphi\left(x_{1}, y_{1}\right) \varphi\left(a_{2}, b_{2}\right)\right]=\left[\varphi\left(a_{2}, b_{2}\right) \varphi\left(x_{2}, y_{2}\right) \varphi\left(a_{2}, b_{2}\right)\right]
$$

or

$$
\left[\varphi\left(a_{2}, b_{2}\right)\left(x_{1}^{\prime}, y_{1}^{\prime}\right) \varphi\left(a_{2}, b_{2}\right)\right]=\left[\varphi\left(a_{2}, b_{2}\right)\left(x_{2}^{\prime}, y_{2}^{\prime}\right) \varphi\left(a_{2}, b_{2}\right)\right] .
$$

Since the last equality is valid for every $\left(x_{1}^{\prime}, y_{1}^{\prime}\right),\left(x_{2}^{\prime}, y_{2}^{\prime}\right) \in K\left(\Omega_{1}^{\prime}, \Omega_{2}^{\prime}\right)$ satisfying (2), we have $\varphi\left(a_{2}, b_{2}\right)\left(\Omega_{1}^{\prime}, \Omega_{2}^{\prime}\right) \subset \overline{\varphi\left(a_{1}, b_{1}\right)\left(\Omega_{1}^{\prime}, \Omega_{2}^{\prime}\right)}$.

The following two lemmas are immediate consequences of Lemma 1.

Lemma 2. Let $\left(a_{1}, b_{1}\right),\left(a_{2}, b_{2}\right) \in K\left(\Omega_{1}, \Omega_{2}\right)$. If

$$
\left(a_{1}, b_{1}\right)\left(\Omega_{1}, \Omega_{2}\right) \cap\left(a_{2}, b_{2}\right)\left(\Omega_{1}, \Omega_{2}\right) \neq \varnothing,
$$

then

$$
\overline{\varphi\left(a_{1}, b_{1}\right)\left(\Omega_{1}^{\prime}, \Omega_{2}^{\prime}\right)} \cap \overline{\varphi\left(a_{2}, b_{2}\right)\left(\Omega_{1}^{\prime}, \Omega_{2}^{\prime}\right)} \neq \varnothing .
$$

Lemma 3. Let $\left(a_{1}, b_{1}\right),\left(a_{2}, b_{2}\right),\left(a_{3}, b_{3}\right) \in K\left(\Omega_{1}, \Omega_{2}\right)$. The equation

$$
\left[\left(a_{2}, b_{2}\right)\left(a_{1}, b_{1}\right)\left(x_{2}, y_{2}\right)\right]=\left(a_{3}, b_{3}\right)
$$

has a solution for $\left(x_{2}, y_{2}\right) \in K\left(\Omega_{1}, \Omega_{2}\right)$ if and only if there exist $n$-sized elements $T_{1}$ and $T_{2}$ such that

$$
T_{1} \subset b_{2} a_{1} \Omega_{1}, T_{2} \subset a_{2} b_{1} \Omega_{2}, a_{3} \Omega_{1} \subset \operatorname{Int} T_{2}, b_{3} \Omega_{2} \subset \operatorname{Int} T_{1} .
$$

Let $(\alpha, \beta) \in \Omega_{1} \times \Omega_{2}$. We say that an infinite sequence $\left\{\left(a_{i}, b_{i}\right)\right\}_{i=1}^{\infty}$ of elements $\left(a_{i}, b_{i}\right) \in K\left(\Omega_{1}, \Omega_{2}\right)$ has a limit $(\alpha, \beta)$, if the following conditions are satisfied:

a) $\left(\cap_{i=2}^{\infty} b_{i} \Omega_{2}, \cap_{i=2}^{\infty} a_{i} \Omega_{1}\right)=(\alpha, \beta)$,

b) for every $i$ there exists an element $\left(x_{i+1}, y_{i+1}\right)$ such that

$$
\left[\left(a_{i+1}, b_{i+1}\right)\left(a_{i}, b_{i}\right)\left(x_{i+1}, y_{i+1}\right)\right]=\left(a_{i+2}, b_{i+2}\right) .
$$

A sequence $\left\{\left(a_{i}, b_{i}\right)\right\}_{i=1}^{\infty}$ of elements $\left(a_{i}, b_{i}\right) \in K\left(\Omega_{1}, \Omega_{2}\right)$ converging to the point $(\alpha, \beta) \in \Omega_{1} \times \Omega_{2}$ can be built, for example, as follows. Suppose that $E_{1} \subset \Omega_{1}$ is a closed $n$-ball centered at $\alpha$ and $T_{1} \subset \Omega_{2}$ is a closed $n$-ball centered at $\beta$. There exists $\left(a_{1}, b_{1}\right) \in K\left(\Omega_{1}, \Omega_{2}\right)$ such that

$$
\alpha \in b_{1} \Omega_{2} \subset \text { Int } E_{1}, \beta \in a_{1} \Omega_{1} \subset \operatorname{IntT}_{1} .
$$

Suppose now that $E_{2}$ is a closed $n$-ball in $b_{1} \Omega_{2}$ and centered at $\alpha$ and $T_{2}$ is a closed $n$-ball in $a_{1} \Omega_{1}$ and centered at $\beta$. Then, there exists an element $\left(a_{2}, b_{2}\right) \in K\left(\Omega_{1}, \Omega_{2}\right)$ such that

$$
\alpha \in b_{2} \Omega_{2} \subset \text { Int } E_{2}, \beta \in a_{2} \Omega_{1} \subset \text { IntT } T_{2} .
$$

Let $\alpha_{1}=\left(b_{2} a_{1}\right)^{-1}(\alpha)$ and $\beta_{1}=\left(a_{2} b_{1}\right)^{-1}(\beta)$. Let $A_{1} \subset \Omega_{1}$ be a closed $n$-ball centered at $\alpha_{1}$ and $B_{1} \subset \Omega_{2}$ be a closed $n$-ball centered at $\beta_{1}$. Clearly,

$$
\alpha \in b_{2} a_{1} A_{1} \cap E_{2}, \beta \in a_{2} b_{1} B_{1} \cap T_{2} .
$$

Let $E_{3} \subset \operatorname{Int}\left(b_{2} a_{1} A_{1} \cap E_{2}\right)$ be a closed $n$-ball centered at $\alpha$, and let $T_{3} \subset \operatorname{Int}\left(a_{2} b_{1} B_{1} \cap T_{2}\right)$ be a closed $n$-ball centered at $\beta$. Then, there exists an element $\left(a_{3}, b_{3}\right) \in K\left(\Omega_{1}, \Omega_{2}\right)$ such that

$$
\alpha \in b_{3} \Omega_{2}, \quad \beta \in a_{3} \Omega_{1}
$$

and

$$
b_{3} \Omega_{2} \subset \text { Int } E_{3}, \quad a_{3} \Omega_{1} \subset \text { Int } T_{3} .
$$

By Lemma 3 , the point $x_{2}=\left(a_{2} b_{1}\right)^{-1} a_{3}, y_{2}=\left(b_{2} a_{1}\right)^{-1} b_{3}$ is the solution of the equation

$$
\left[\left(a_{2}, b_{2}\right)\left(a_{1}, b_{1}\right)\left(x_{2}, y_{2}\right)\right]=\left(a_{3}, b_{3}\right) .
$$


Assume now that the first $n$ terms of the sequence are already found. Denote $\alpha_{n-1}=\left(b_{n} a_{n-1}\right)^{-1}(\alpha)$ and $\beta_{n-1}=\left(a_{n} b_{n-1}\right)^{-1}(\beta)$. Suppose that $A_{n-1} \subset \Omega_{1}$ is a closed $n$-ball centered at $\alpha_{n-1}$ and $B_{n-1} \subset \Omega_{2}$ is a closed $n$-ball centered at $\beta_{n-1}$. Clearly,

$$
\alpha \in b_{n} a_{n-1} A_{n-1} \cap E_{n}, \beta \in a_{n} b_{n-1} B_{n-1} \cap T_{n} .
$$

Let $E_{n+1} \subset \operatorname{Int}\left(b_{n} a_{n-1} A_{n-1} \cap E_{n}\right)$ be a closed $n$-ball centered at $\alpha$, and let $T_{n+1} \subset \operatorname{Int}\left(a_{n} b_{n-1} B_{n-1} \cap T_{n}\right)$ be a closed $n$-ball centered at $\beta$. Then, there exists an element $\left(a_{n+1}, b_{n+1}\right) \in K\left(\Omega_{1}, \Omega_{2}\right)$ such that

$$
\alpha \in b_{n+1} \Omega_{2}, \beta \in a_{n+1} \Omega_{1}
$$

and

$$
b_{n+1} \Omega_{2} \subset \operatorname{Int} E_{n+1}, a_{n+1} \Omega_{1} \subset \operatorname{Int} T_{n+1} .
$$

By Lemma 3, the point $x_{n}=\left(a_{n} b_{n-1}\right)^{-1} a_{n+1}, y_{n}=\left(b_{n} a_{n-1}\right)^{-1} b_{n+1}$ is the solution of the equation

$$
\left[\left(a_{n}, b_{n}\right)\left(a_{n-1}, b_{n-1}\right)\left(x_{n}, y_{n}\right)\right]=\left(a_{n+1}, b_{n+1}\right) .
$$

This sequence satisfies condition $(b)$ and condition $(a)$, if the sequences of radii of $E_{n}$ and $T_{n}$ converge to zero.

Lemma 4. If the ternary semigroups $K\left(\Omega_{1}, \Omega_{2}\right)$ and $K\left(\Omega_{1}^{\prime}, \Omega_{2}^{\prime}\right)$ are isomorphic, then there exist a bijective map $f$ from $\Omega_{1} \times \Omega_{2}$ onto $\Omega_{1}^{\prime} \times \Omega_{2}^{\prime}$ and bijective maps $\xi_{i}$ from $\Omega_{i}$ onto $\Omega_{i}^{\prime}(i=1,2)$ such that $f(\alpha, \beta)=\left(\xi_{1} \alpha, \xi_{2} \beta\right)$ for every $(\alpha, \beta) \in \Omega_{1} \times \Omega_{2}$.

Proof. Let $(\alpha, \beta)$ be any point in $\Omega_{1} \times \Omega_{2}$ and let $\left\{\left(a_{i}, b_{i}\right)\right\}_{i=1}^{\infty}$ be a sequence of elements $\left(a_{i}, b_{i}\right) \in B\left(\Omega_{1}, \Omega_{2}\right)$ converging to the point $(\alpha, \beta)$. Denote $\varphi\left(a_{i}, b_{i}\right)$ by $\left(a_{i}^{\prime}, b_{i}^{\prime}\right)$. The sequence $\left\{\left(a_{i}^{\prime}, b_{i}^{\prime}\right)\right\}_{i=1}^{\infty}$ converges to the point $\left(\alpha^{\prime}, \beta^{\prime}\right)$. Define a map $f:\left(\Omega_{1}, \Omega_{2}\right) \rightarrow\left(\Omega_{1}^{\prime}, \Omega_{2}^{\prime}\right)$ by $f(\alpha, \beta)=\left(\alpha^{\prime}, \beta^{\prime}\right)$. The point $\left(\alpha^{\prime}, \beta^{\prime}\right)$ does not depend on the choice of the sequence $\left\{\left(a_{i}, b_{i}\right)\right\}_{i=1}^{\infty}$ of elements $\left(a_{i}, b_{i}\right) \in B\left(\Omega_{1}, \Omega_{2}\right)$ converging to the point $(\alpha, \beta)$. The map $f$ is one-to-one and there are one-to-one maps $\xi_{i}$ from $\Omega_{i}$ onto $\Omega_{i}^{\prime}$ for $(i=1,2)$ such that $\forall(\alpha, \beta) \in \Omega_{1} \times \Omega_{2}, f(\alpha, \beta)=$ $=\left(\xi_{1} \alpha, \xi_{2} \beta\right)$.

Lemma 5. 1) The following implication holds

$$
(\alpha, \beta) \in(a, b)\left(\Omega_{1}, \Omega_{2}\right) \rightarrow f(\alpha, \beta)=\left(\xi_{1} \alpha, \xi_{2} \beta\right) \in \overline{\varphi(a, b)\left(\Omega_{1}^{\prime}, \Omega_{2}^{\prime}\right)}
$$

for any $(\alpha, \beta) \in \Omega_{1} \times \Omega_{2}$ and $(a, b) \in K\left(\Omega_{1}, \Omega_{2}\right)$.

2) The map $f$ is a homeomorphism from $\Omega_{1} \times \Omega_{2}$ onto $\Omega_{1}^{\prime} \times \Omega_{2}^{\prime}$ and therefore the map $\xi_{i}$ is a homeomorphism from $\Omega_{i}$ onto $\Omega_{i}^{\prime}$ for $i=1,2$.

Theorem 2. The ternary semigroup $K\left(\Omega_{1}, \Omega_{2}\right)$ is a minimal ideal (the kernel) of the ternary semigroup $O H\left(\Omega_{1}, \Omega_{2}\right)$.

Theorem 3. Let $\Omega_{1}$ and $\Omega_{2}$ be open subsets of a finite-dimensional Euclidean space $R$ and $\Omega_{1}^{\prime}$ and $\Omega_{2}^{\prime}$ be open subsets of a finite-dimensional Euclidean space $R^{\prime}$. The ternary semigroups $O H\left(\Omega_{1}, \Omega_{2}\right)$ and $O H\left(\Omega_{1}^{\prime}, \Omega_{2}^{\prime}\right)$ are isomorphic if and only if the spaces $\Omega_{i}$ and $\Omega_{i}^{\prime}$ are homeomorphic $(i=1,2)$.

\section{Properties of the ternary semigroup of topological maps}

Let $G$ be a group and let $A=G \cup\{0\}$ be a zero adjoint semigroup. Let $I, \Lambda$ be non-empty sets and let $P$ be a $\Lambda \times I$ matrix over $A$ such that every row and every column of $P$ contain at least one non-zero entry. The set $S=A \times I \times \Lambda$ with ternary multiplication

$$
[(a ; i, \lambda)(b ; j, \mu)(c ; k, \nu)]=\left(a p_{\lambda j} b p_{\mu k} c ; i, \nu\right)
$$

is a ternary semigroup with zero $0=(0, i, \lambda)$. Let $(A, i, \lambda)$ denote a subset of $S$ consisting of all triples $(a, i, \lambda)$, where $a \in A$ and $i, \lambda$ are fixed elements, then

$$
S=\bigcup_{i \in I, \lambda \in \Lambda}(A, i, \lambda) .
$$

From the definition of the ternary operation it follows that $S$ is the union of its nonzero minimal right ideals $R_{i}$ and $S$ is the union of its nonzero minimal left ideals $L_{\lambda}$, where

$$
R_{i}=\underset{\lambda \in \Lambda}{\cup}(A, i, \lambda), \quad L_{\lambda}=\cup_{i \in I}(A, i, \lambda) .
$$

Mathematics series. № 2(102)/2021 
The ternary semigroup $S$ does not contain any proper two sided ideals, in particular, $S$ does not contain any proper ideals. We denote $S$ by $M^{0}(G, I, \Lambda, P)$.

Let $R$ and $R^{\prime}$ be finite-dimensional Euclidean spaces, $\Omega_{1}$ and $\Omega_{2}$ be open subsets of a finite-dimensional Euclidean space $R$ and let $\Omega_{1}^{\prime}$ and $\Omega_{2}^{\prime}$ be open subsets of a finite-dimensional Euclidean space $R^{\prime}$. Suppose that $\xi_{1}: \Omega_{1} \rightarrow \Omega_{1}^{\prime}$ is a homeomorphism of $\Omega_{1}$ onto $\Omega_{1}^{\prime}$ and $\xi_{2}: \Omega_{2} \rightarrow \Omega_{2}^{\prime}$ is a homeomorphism of $\Omega_{2}$ onto $\Omega_{2}^{\prime}$. Then, the mapping $\varphi_{\xi_{1}, \xi_{2}}: K\left(\Omega_{1}, \Omega_{2}\right) \rightarrow K\left(\Omega_{1}^{\prime}, \Omega_{2}^{\prime}\right)$ defined by

$$
\varphi_{\xi_{1}, \xi_{2}}(a, b)=\left(\xi_{2} a \xi_{1}^{-1}, \xi_{1} b \xi_{2}^{-1}\right)
$$

is a homeomorphism from $K\left(\Omega_{1}, \Omega_{2}\right)$ onto $K\left(\Omega_{1}^{\prime}, \Omega_{2}^{\prime}\right)$.

Introduce the following symmetric and reflexive relation $\sigma_{r}$ in the ternary semigroup $O H\left(\Omega_{1}, \Omega_{2}\right):\left(a_{1}, b_{1}\right)$, $\left(a_{2}, b_{2}\right) \in \sigma_{r}$ if and only if $\left(a_{1}, b_{1}\right)=\left(a_{2}, b_{2}\right)$ or $\left(a_{1}, b_{1}\right),\left(a_{2}, b_{2}\right) \in R_{(a, b)}$ for some $(a, b) \in O H\left(\Omega_{1}, \Omega_{2}\right)$, where $R_{(a, b)}$ is a right ideal of $O H\left(\Omega_{1}, \Omega_{2}\right)$ generated by $(a, b)$. Since the relation $\sigma_{r}$ is stable, its transitive closure $\overline{\sigma_{r}}$ is a congruence on $O H\left(\Omega_{1}, \Omega_{2}\right)$. Each equivalence class $R_{\alpha}$ of $\overline{\sigma_{r}}$ either consists of one element of $O H\left(\Omega_{1}, \Omega_{2}\right)$ not contained in $K\left(\Omega_{1}, \Omega_{2}\right)$ or is a right ideal of $O H\left(\Omega_{1}, \Omega_{2}\right)$. Then,

$$
K\left(\Omega_{1}, \Omega_{2}\right)=\cup_{\alpha \in I} R_{\alpha}
$$

is the most fractional partition of $K\left(\Omega_{1}, \Omega_{2}\right)$ into pairwise disjoint union of the distinct right ideals of $O H\left(\Omega_{1}, \Omega_{2}\right)$.

Let $A_{i}$ be some component of the set $\Omega_{1}, B_{\mu}$ be some component of the set $\Omega_{2}$ and $R_{i \mu}$ be a subset of the ternary semigroup $K\left(\Omega_{1}, \Omega_{2}\right)$ consisting of $(a, b)$ such that $a \Omega_{1} \subset B_{\mu}, b \Omega_{2} \subset A_{i}$. If $(a, b)$ is any element of $R_{i \mu}$ and $\left(x_{1}, y_{1}\right),\left(x_{2}, y_{2}\right)$ are the elements of the ternary semigroup $O H\left(\Omega_{1}, \Omega_{2}\right)$, then from $a \Omega_{1} \subset B_{\mu}, b \Omega_{2} \subset A_{i}$ it follows that

$$
a y_{1} x_{2} \Omega_{1} \subset B_{\mu}, \quad b x_{1} y_{2} \Omega_{2} \subset A_{i} .
$$

Thus, $\left(a y_{1} x_{2}, b x_{1} y_{2}\right) \in R_{i \mu}$ and $R_{i \mu}$ is a right ideal of $O H\left(\Omega_{1}, \Omega_{2}\right)$. Consequently, the partition

$$
K\left(\Omega_{1}, \Omega_{2}\right)=\underset{i \in I, \mu \in M}{\cup} R_{i \mu}
$$

is the presentation of $K\left(\Omega_{1}, \Omega_{2}\right)$ as the pairwise disjoint union of the distinct right ideals of $O H\left(\Omega_{1}, \Omega_{2}\right)$.

Lemma 6 . If $E_{i}$ is any closed ball contained in $\Omega_{i}$, and $\alpha_{i}, \beta_{i}$ are any points in Int $E_{i}$, then there is $\left(b_{1}, b_{2}\right) \in K\left(\Omega_{1}, \Omega_{2}\right)$ such that

$$
\alpha_{i}, \beta_{i} \in b_{j} \Omega_{j}, \quad b_{j} \Omega_{j} \subset \operatorname{Int} E_{i},
$$

where $i, j=1,2(i \neq j)$.

Proof. Let $\left(a_{1}, a_{2}\right)$ be an arbitrary element in $K\left(\Omega_{1}, \Omega_{2}\right), C_{i}$ be a closed ball in $a_{j} \Omega_{j}$ and $A_{i}, B_{i}, D_{i}$ be any closed balls such that

$$
\Omega_{i} \subset \operatorname{Int} E_{i}, \quad B_{i} \subset \operatorname{Int} D_{i}, \quad D_{i} \subset \text { Int } E_{i}, \quad \alpha_{i}, \beta_{i} \in \operatorname{Int} B_{i} .
$$

Futher, let $f_{i}$ be the homeomorphisms of $A_{i}$ onto $D_{i}$ such that $f_{i}\left(C_{i}\right)=B_{i}$. Then $\left(b_{1}, b_{2}\right)=\left(f_{2} a_{1}, f_{1} a_{2}\right)$ is the requiered element of $K\left(\Omega_{1}, \Omega_{2}\right)$.

Lemma 7. The partition

$$
K\left(\Omega_{1}, \Omega_{2}\right)=\underset{i \in I, \mu \in M}{\cup} R_{i \mu}
$$

is the most fractional partition of $K\left(\Omega_{1}, \Omega_{2}\right)$ into pairwise disjoint right ideals of $O H\left(\Omega_{1}, \Omega_{2}\right)$.

Proof. It is sufficient to show that for any $i \in I, \mu \in M$ the condition

$$
\left(a_{0}, b_{0}\right),(a, b) \in R_{i \mu}
$$

implies

$$
\left(a_{0}, b_{0}\right),(a, b) \in \overline{\sigma_{r}} .
$$

Let's prove this for the maps $b_{0}$ and $b$ from $\Omega_{2}$ into $A_{i}$, where $A_{i}$ is a component of $\Omega_{1}$. Let $\xi \in b_{0} \Omega_{2}, \quad \xi^{\prime} \in b \Omega_{2}$. Since $\xi, \xi^{\prime} \in A_{i}$, they can be connected by a simple arc $l$ contained in $A_{i}$. We have $d\left(F_{r}\left(A_{i}\right), l\right)=m>0$, where $F_{r}\left(A_{i}\right)$ is a boundary of $A_{i}$. Then, it can be found finite covering of $l$ with open balls of radius $r<m$ centered on $l$. Denote these balls by $E_{2 k}(k=1,2, \ldots, s)$, numerated in order of their centers positions on $l$. Choose points

$$
\xi_{k} \in E_{2 k} \cap E_{2 k+2},(k=1,2, \ldots, s-1)
$$


and denote $\xi_{0}=\xi, \xi_{s}=\xi^{\prime}$. Since $\overline{E_{2 k}} \subset A_{i}$, there are closed balls $D_{2 k}$ in $\overline{E_{2 k}}$ such that $\xi_{k-1}, \xi_{k} \in$ Int $D_{2 k}$. According to Lemma 1 there exists a homeomorphism $b_{2 k}$ from $\Omega_{2}$ to $\Omega_{1}$ such that $b_{2 k} \Omega_{2} \subset$ Int $D_{2 k}$ and

$$
\xi_{k-1}, \xi_{k} \in b_{2 k} \Omega_{2},(k=1,2, \ldots, s-1) .
$$

Denote $b=b_{2 s+2}$. There are closed sets $E_{2 i+1}$ and $E_{2 i+1}^{\prime}$ centered at $\xi_{i}$ such that $E_{2 i+1} \subset E_{2 i+1}^{\prime} \subset b_{2 i} \Omega_{2} \cap$ $\cap b_{2 i+2},(k=1,2, \ldots, s)$. By Lemma 1 , there exists a homeomorphism $b_{2 k+1}$ from $\Omega_{2}$ to $\Omega_{1}$ such that $b_{2 i+1} \Omega_{2} \subset$ Int $E_{2 i+1}$. Let $E$ be a closed $n$-ball containing the set $\Omega_{1}$ and let $\widetilde{E}$ be a closed $n$-ball contained in $\Omega_{1}$. If $f_{2 i+1}$ is a homeomorphism from $E$ onto $E_{2 i+1}^{\prime}$ for which $f_{2 i+1}(\widetilde{E})=E_{2 i+1}$, then

$$
\begin{aligned}
& b_{2 i+1}=b_{2 i} \circ b_{2 i}^{-1} f_{2 i+1} \circ f_{2 i+1}^{-1} b_{2 i+1}, \\
& b_{2 i+1}=b_{2 i+2} \circ b_{2 i+2}^{-1} f_{2 i+1} \circ f_{2 i+1}^{-1} b_{2 i+1},
\end{aligned}
$$

where $k=0,1,2, \ldots, s$. Analogously, it can be shown that the following equations hold for some homeomorphism $g_{2 i+1}$

$$
\begin{aligned}
& a_{2 i+1}=a_{2 i} \circ a_{2 i}^{-1} g_{2 i+1} \circ g_{2 i+1}^{-1} a_{2 i+1}, \\
& a_{2 i+1}=a_{2 i+2} \circ a_{2 i+2}^{-1} g_{2 i+1} \circ g_{2 i+1}^{-1} a_{2 i+1},
\end{aligned}
$$

where $j=0,1,2, \ldots, s^{\prime}$ and $a_{2 s^{\prime}+2}=a$. Suppose that $s<s^{\prime}$. Thus, $\left(a_{i-1}, b_{i-1}\right),\left(a_{i}, b_{i}\right) \in \overline{\sigma_{r}}$ for $i=1,2, \ldots, 2 s+2$ and

$$
\left(a_{j-1}, b_{2 s+2}\right),\left(a_{j}, b_{2 s+2}\right) \in \overline{\sigma_{r}} \text { fori }=1,2, \ldots, 2 s+2 .
$$

This means that $\left(a_{0}, b_{0}\right),(a, b) \in \overline{\sigma_{r}}$.

Analogously, it can be shown that

$$
K\left(\Omega_{1}, \Omega_{2}\right)=\underset{i \in I, \mu \in M}{\cup} R_{i \mu}
$$

is the most fractional partition of $K\left(\Omega_{1}, \Omega_{2}\right)$ into pairwise disjoint right ideals.

Theorem 4. The quotient $O H\left(\Omega_{1}, \Omega_{2}\right) / \overline{\sigma_{r}}$ is a ternary semigroup with the minimal ideal $K\left(\Omega_{1}, \Omega_{2}\right) / \overline{\sigma_{r}}$.

Proof. Since $K\left(\Omega_{1}, \Omega_{2}\right)$ is an ideal of $O H\left(\Omega_{1}, \Omega_{2}\right)$ the quotient $K\left(\Omega_{1}, \Omega_{2}\right) / \overline{\sigma_{r}}$ is an ideal of $O H\left(\Omega_{1}, \Omega_{2}\right) / \overline{\sigma_{r}}$. It follows from Lemma 2 that the elements of $K\left(\Omega_{1}, \Omega_{2}\right) / \overline{\sigma_{r}}$ are the classes $R_{i \lambda}$. Let $G=\{e\}$ be the unit group, and let $P$ be a $\Lambda \times I$ matrix over $G$. Denote by $T$ the completely simple ternary semigroup over $G=\{e\}$. To each element $R_{i \lambda}$ of $K\left(\Omega_{1}, \Omega_{2}\right) / \overline{\sigma_{r}}$ assign an element $(e ; i, \lambda)$ of $T$. The map $f$ is the isomorphism from $K\left(\Omega_{1}, \Omega_{2}\right) / \overline{\sigma_{r}}$ onto $T$. Indeed,

$$
\begin{gathered}
f\left(\left[R_{i \lambda} R_{j \mu} R_{k \nu}\right]\right)=f\left(R_{i \nu}\right)=(e ; i, \nu) \\
=[(e ; i, \lambda)(e ; j, \mu)(e ; k, \nu)]=\left[f\left(R_{i \lambda}\right) f\left(R_{j \mu}\right) f\left(R_{k \nu}\right)\right] .
\end{gathered}
$$

Theorem 5. The ternary semigroup $K\left(\Omega_{1}, \Omega_{2}\right) / \overline{\sigma_{r}}$ is a topological invariant of the pair $\left(\Omega_{1}, \Omega_{2}\right)$.

Proof. Let $\Omega_{1}$ and $\Omega_{2}$ be open subsets of a finite-dimensional Euclidean space $R^{n}$ and let $\Omega_{1}^{\prime}$ and $\Omega_{2}^{\prime}$ be open subsets of a finite-dimensional Euclidean space $R^{m}$. If $\xi_{i}: \Omega_{i} \rightarrow \Omega_{i}^{\prime}(i=1,2)$ is a homeomorphism, then the mapping $f: K\left(\Omega_{1}, \Omega_{2}\right) \rightarrow K\left(\Omega_{1}^{\prime}, \Omega_{2}^{\prime}\right)$ defined by

$$
f(a, b)=\left(\xi_{2} a \xi_{1}^{-1}, \xi_{1} b \xi_{2}^{-1}\right)
$$

is an isomorphism from $K\left(\Omega_{1}, \Omega_{2}\right)$ onto $K\left(\Omega_{1}^{\prime}, \Omega_{2}^{\prime}\right)$. In the case of $\xi_{1}$ the component $A_{i} \subset \Omega_{1}$ is mapped onto the component $A_{i^{\prime}}^{\prime} \subset \Omega_{1}^{\prime}$, in the case of $\xi_{2}$ the component $B_{\lambda} \subset \Omega_{2}$ is mapped onto the component $B_{\lambda^{\prime}}^{\prime} \subset \Omega_{2}^{\prime}$. Therefore $K\left(\Omega_{1}, \Omega_{2}\right) / \overline{\sigma_{r}}$ is isomorphic to $K\left(\Omega_{1}^{\prime}, \Omega_{2}^{\prime}\right) / \overline{\sigma_{r}}$.

The following three theorems are immediate consequences of Lemma 7.

Theorem 6 . The spaces $\Omega_{1}$ and $\Omega_{2}$ are connected if and only if the ternary semigroup $K\left(\Omega_{1}, \Omega_{2}\right)$ cannot be represented as the pairwise disjoint union of its distinct right ideals.

Theorem \%. If the quotient $K\left(\Omega_{1}, \Omega_{2}\right) / \overline{\sigma_{r}}$ is finite and its order is a prime number, then one of the spaces $\Omega_{1}$ and $\Omega_{2}$ is connected.

Theorem 8. Let $\Omega_{1}$ and $\Omega_{2}$ be open subsets of a finite-dimensional Euclidean space. The space $\Omega_{2}$ is connected if and only if the quotient $K\left(\Omega_{1}, \Omega_{2}\right) / \overline{\sigma_{r}}$ is a ternary semigroup of left zeros, the space $\Omega_{1}$ is connected if and only if the quotient $K\left(\Omega_{1}, \Omega_{2}\right) / \overline{\sigma_{r}}$ is a ternary semigroup of right zeros.

Theorem 9. If at least one of the ternary semigroups $R_{i \mu}$ in the partition $K\left(\Omega_{1}, \Omega_{2}\right)=\underset{i \in I, \mu \in M}{\cup} R_{i \mu}$ is simple, then the spaces $\Omega_{1}$ and $\Omega_{2}$ are connected. 
Proof. Introduce the following relation $\rho_{i \mu}$ in the ternary semigroup $R_{i \mu}: \forall\left(\varphi_{1}, \phi_{1}\right)$,

$\left(\varphi_{2}, \phi_{2}\right) \in R_{i \mu},\left(\left(\varphi_{1}, \phi_{1}\right),\left(\varphi_{2}, \phi_{2}\right)\right) \in \rho_{i \mu}$ if and only if $\forall \xi \in A_{i}, \eta \in B_{\mu}, \varphi_{1}(\xi)=\varphi_{2}(\xi), \phi_{1}(\eta)=\phi_{2}(\eta)$. The relation $\rho_{i \mu}$ is a congruence on $R_{i \mu}$. Indeed, if $\left(\varphi_{1}, \phi_{1}\right),\left(\varphi_{2}, \phi_{2}\right)$ are any two elements of $R_{i \mu}$ such that $\left(\left(\varphi_{1}, \phi_{1}\right),\left(\varphi_{2}, \phi_{2}\right)\right) \in \rho_{i \mu}$ and $\left(x_{1}, y_{1}\right),\left(x_{2}, y_{2}\right) \in R_{i \mu}$, then

$$
\begin{gathered}
\left(\varphi_{1}, \phi_{1}\right) \stackrel{\rho_{i \mu}}{\sim}\left(\varphi_{2}, \phi_{2}\right) \rightarrow\left\{\forall \xi \in A_{i}, \eta \in B_{\mu},\left(x_{i}, y_{i}\right) \in R_{i \mu}\right. \\
\left.\varphi_{1} y_{2} x_{1}(\xi)=\varphi_{2} y_{2} x_{1}(\xi), y_{1} x_{2} \phi_{1}(\eta)=y_{1} x_{2} \phi_{2}(\eta)\right\} \rightarrow \\
\forall\left(x_{i}, y_{i}\right) \in R_{i \mu}, \\
\left(\left[\left(x_{1}, y_{1}\right)\left(x_{2}, y_{2}\right)\left(\varphi_{1}, \phi_{1}\right)\right],\left[\left(x_{1}, y_{1}\right)\left(x_{2}, y_{2}\right)\left(\varphi_{2}, \phi_{2}\right)\right]\right) \in \rho_{i \mu} .
\end{gathered}
$$

Analogously, it can be shown that

$$
\begin{aligned}
& \left(\left[\left(x_{1}, y_{1}\right)\left(\varphi_{1}, \phi_{1}\right)\left(x_{2}, y_{2}\right)\right],\left[\left(x_{1}, y_{1}\right)\left(\varphi_{2}, \phi_{2}\right)\left(x_{2}, y_{2}\right)\right]\right) \in \rho_{i \mu}, \\
& \left(\left[\left(\varphi_{1}, \phi_{1}\right)\left(x_{1}, y_{1}\right)\left(x_{2}, y_{2}\right)\right],\left[\left(\varphi_{2}, \phi_{2}\right)\left(x_{1}, y_{1}\right)\left(x_{2}, y_{2}\right)\right]\right) \in \rho_{i \mu} .
\end{aligned}
$$

Consider the mapping $f(\varphi, \phi)=\left(\varphi^{\prime}, \phi^{\prime}\right)$ from $R_{i \mu}$ to $K\left(A_{i}, B_{\mu}\right)$ such that

$$
\left.\varphi\right|_{A_{i}}=\varphi^{\prime},\left.\phi\right|_{B_{\mu}}=\phi^{\prime}
$$

Clearly, the mapping $f$ is a homomorphism of $R_{i \mu}$ to $K\left(A_{i}, B_{\mu}\right)$. Now, let the ternary semigroup $R_{i \mu}$ be simple and let at least one of the spaces $\Omega_{1}$ or $\Omega_{2}$ be connected. Suppose that $\Omega_{1}$ is disconnected but $\Omega_{2}$ is connected. The elements $\left(\varphi_{1}, \phi_{1}\right),\left(\varphi_{2}, \phi_{2}\right)$ can be found in $R_{i \mu}$ such that $\left(\left(\varphi_{1}, \phi_{1}\right),\left(\varphi_{2}, \phi_{2}\right)\right) \in \rho_{i \mu}\left(\varphi_{1}, \varphi_{2}\right.$ can map $\Omega_{1}$ to two disjoint balls $E_{1}, E_{2} \subset \Omega_{2}$ and because of this $\left.\varphi_{1}(\xi) \neq \varphi_{2}(\xi), \xi \in \Omega_{1}\right)$. Besides, there are more than one element in each class of $\rho_{i \mu}$. Indeed, if $\varphi$ is a homeomorphism of $\Omega_{1}$ to the closed ball $E_{1} \subset \Omega_{2}$ and $g$ is a homeomorphism of $\Omega_{1}$ to the closed ball $E_{2} \subset \Omega_{2}$ such that $E_{1} \cap E_{2}=\emptyset, E_{1}, E_{2} \subset E_{3}$, where $E_{3}$ is a closed ball in $\Omega_{2}$, then the mapping

$$
\chi(\alpha)=\left\{\begin{array}{l}
\varphi(\alpha), \text { if } \alpha \in A_{i}, \\
g(\alpha), \text { if } \alpha \notin A_{i},
\end{array}\right.
$$

where $A_{i}$ is a component of $\Omega_{1}$, is a homomorphism of $\Omega_{1}$ to $\Omega_{2}$. Clearly, $\chi \neq \varphi$ and $\left.\chi\right|_{A_{i}}=\left.\varphi\right|_{A_{i}}$. Therefore $((\chi, \phi),(\varphi, \phi)) \in \rho_{i 1}$. Here $\phi$ denotes some homeomorphism of $\Omega_{2}$ into the interior of some $n$-element containd in $\Omega_{1}$ and $\rho_{i 1}$ is some congruence on $R_{i 1}\left(B_{1}=\Omega_{2}\right)$. Then it follows that $f$ is a homomorphism from $R_{i 1}$ onto $f\left(R_{i 1}\right) \subset K\left(A_{i}, \Omega_{2}\right)$, which contains more than one element. But $f$ is not an isomorphism, which contradicts the simplicity of $R_{i 1}$.

\section{References}

1 Lehmer D.H. A ternary analogue of Abelian groups / D.H. Lehmer // Am.J. Math. - 1932. - 54. P. $329-338$.

2 Santiago M.L. Ternary semigroups / M.L. Santiago, S. Sri Bala // Semigroup Forum. - 2010. - 81. P. $380-388$.

3 Dutta T.K. On ideals in regular ternary semigroups / T.K. Dutta, S. Kar, B. Maity // Discussiones Mathematicae, General Algebra and Applications. - 2008. - 28. - P. 147-159.

4 Wagner V.V. The theory of generalized heaps and generalized groups / V.V. Wagner // Mat. Sb. NS. 1953. - 32. - No. 74. - P. 545-632.

5 Gluskin L.M. Semigroups of topological transformations / L.M. Gluskin // Izv. vyssh. uchebn. zaved. Mat. - 1963. - 1. - P. 54-65.

6 Mustafaev L.G. Semiheaps of topological maps / L.G. Mustafaev // Dokl. Akad. nauk SSSR. - 1976. 230. - No. 6. - P. 1279-1281.

7 Sheeja G. Simple ternary semigroups / G. Sheeja, S. Sri Bala // Quasigroups and Related Systems. 2013. - 21. - P. 103-116.

8 Kar S. Congruences on ternary semigroups / S.Kar, B. Maity // J. of the Chungcheong Math. Society. 2007. - 20. - P. 191-201. 
Ф.Х. Мурадов

Таяу Шыъыс университеті, Никосия, Түркия

\title{
Топологиялық түрлендірудің тернарлы жартылайтоптары
}

Тернарлы жартылайтоп - бұл ассоциативті тернарлы операциясы бар босемес жиын. Мақаланың мақсаты - ақырлы өлшемді евклид кеңістіктерінің ашық жиынтығын гомеоморфты қайта құру жұптарының тернарлы жартылайтоптарымен сипаттау және Л.М. Глушкиннің ақырлы өлшемді евклид кеңістіктерінің гомеоморфты түрлендірудің жартылайтоптарына қатысты кейбір нәтижелерін теріс жартылайтоптарға тарату.

Kiлm сөздер: Евклид n-кеңістік, тернарлы жартылайтоп, гомеоморфты түрлендіру.

\author{
Ф.Х. Мурадов
}

Ближневосточный университет, Никосия, Турция

\section{Тернарные полугруппы топологических преобразований}

Тернарная полугруппа - это непустое множество с ассоциативной тернарной операцией. Цель настоящей статьи - охарактеризовать открытые множества конечномерных евклидовых пространств тернарными полугруппами пар гомеоморфных преобразований и распространить на тернарные полугруппы некоторые результаты Л.М. Глушкина, касающиеся полугрупп гомеоморфных преобразований конечномерных евклидовых пространств.

Ключевые слова: евклидово $n$-пространство, тернарная полугруппа, гомеоморфные преобразования.

\section{References}

1 Lehmer, D.H. (1932). A ternary analogue of Abelian groups. Am.J. Math., 54, 329-338.

2 Santiago, M.L., \& Sri Bala, S. (2010). Ternary semigroups. Semigroup Forum, 81, 380-388.

3 Dutta, T.K., Kar, S., \& Maity, B. (2008). On ideals in regular ternary semigroups. Discussiones Mathematicae, General Algebra and Applications, 28, 147-159.

4 Waner, V.V. (1953). The theory of generalized heaps and generalized groups. Mat. Sb., NS 32(74), 545-632.

5 Gluskin, L.M. (1963). Semigroups of topological transformations. Izveatiia vysshcikh uchebnykh zavedenii Mat., 1, 54-65.

6 Mustafaev, L.G. (1976). Semiheaps of topological maps. Doklady Akademii nauk SSSR, 230(6), 12791281.

7 Sheeja, G., \& Sri Bala, S. (2013). Simple ternary semigroups. Quasigroups and Related Systems, 21, 103-116.

8 Kar, S., \& Maity ,B. (2007). Congruences on ternary semigroups. J. of the Chungcheong Math. Society, 20, 191-201. 